\title{
A Comparison of Five Adhesive Tapes for Securing Endotracheal Tube in a Manikin
}

\author{
Dongxue Li, Xia Huang, Sanqing Jin* \\ Department of Anesthesia, The Sixth Affiliated Hospital, Sun Yat-sen University, Guangzhou, China \\ Email: *jinsq@mail.sysu.edu.cn
}

How to cite this paper: Li, D.X., Huang, X. and Jin, S.Q. (2021) A Comparison of Five Adhesive Tapes for Securing Endotracheal Tube in a Manikin. International Journal of Clinical Medicine, 12, 451-458. https://doi.org/10.4236/ijcm.2021.1210041

Received: September 29, 2021

Accepted: October 19, 2021

Published: October 22, 2021

Copyright (c) 2021 by author(s) and Scientific Research Publishing Inc. This work is licensed under the Creative Commons Attribution International License (CC BY 4.0).

http://creativecommons.org/licenses/by/4.0/ (c) (i) Open Access

\begin{abstract}
Background: Adhesive tape is the common method for endotracheal tube (ETT) secured to prevent tube displacement and unplanned extubation in an anesthesia setting. However, it is unclear which tape is superior for ETT fixation among the various tapes used in clinical practice. This study examines the force required to move $2 \mathrm{~cm}$ ETT and extubate ETT from an intubation manikin with five different adhesive tapes. Methods: We orally intubated an adult intubation manikin with an inner-diameter $7.5 \mathrm{~mm}$ ETT, inflated the cuff to $20 \mathrm{~cm} \mathrm{H}_{2} \mathrm{O}$. Then we secured ETT with five different adhesive tapes (Transpore tape $^{\mathrm{TM}}$, Urgosyval tape ${ }^{\circledR}$, Transpore ${ }^{\mathrm{TM}}$ White tape, Multipore tape, Durapore $^{\mathrm{TM}}$ tape) in a conventional fixation method. A digital force gauge was connected to the ETT and pulled in a direction erected to the oral cavity. We measured the force required to move $2 \mathrm{~cm}$ ETT and extubate ETT (defined as $5 \mathrm{~cm}$ ETT displacement) from the manikin. Data were analyzed with one-way analysis of variance, with $P<0.05$. Results: Durapore ${ }^{\mathrm{TM}}$ tape had the largest average force of $2 \mathrm{~cm}$ displacement $(58.9 \pm 5.7 \mathrm{~N})(P<0.05)$. The extubation force of Durapore ${ }^{\mathrm{TM}}$ tape $(59.7 \pm 4.9 \mathrm{~N})$ was larger than Urgosyval ${ }^{\circledR}$ tape $(40.4 \pm 2.9 \mathrm{~N})(P<0.05)$, Transpore ${ }^{\mathrm{TM}}$ tape $(48.7 \pm 5.1 \mathrm{~N})(P<0.05)$, Transpore White ${ }^{\mathrm{TM}}$ tape $(48.7 \pm 5.1 \mathrm{~N})(P<0.05)$. Conclusion: Durapore ${ }^{\mathrm{TM}}$ tape was superior to the other four tapes (Transpore ${ }^{\mathrm{TM}}$ tape, Urgosyval ${ }^{\circledR}$ tape, Transpore $^{\mathrm{TM}}$ white tape, Multipore tape) in holding the ETT in place in the manikin.
\end{abstract}

\section{Keywords}

Adhesive Tape, Extubation Force, Endotracheal Tube Fixation, Manikin

\section{Introduction}

Adequate endotracheal tube (ETT) fixation in an intubation patient is essential to prevent potentially life-threatening complications. During the general anes- 
thesia, ETT displacement or accidental extubation may occur at any time for various reasons. ETT displacement or accidental extubation may occur when a patient is being transported [1]. It may happen when the surgeon requires frequent movement of head or neck to exposure certain surgery site [2].

ETT displacement or accidental extubation may lead to atelectasis formation, vocal cord injury, aspiration, respiratory arrest, hypoxemia, hypotension, cardiac arrest, anoxic brain injury, or even death [3] [4] [5] [6] [7]. Hence, the fixation of ETT is of utmost importance as not only provides effective ventilation but also minimizes complications due to accidental extubation.

Many devices and techniques to secure ETT are in use, including tape, ETT holders, twill, sucture, etc. Comparisons of adhesive tape versus ETT holder have not demonstrated that either is superior [8]-[14]. Tape is primarily used in the operating room at our institution. However, it is unclear which tape is superior for ETT fixation among the various tapes used in clinical practice. In the work, we usually choose the strong adhesion, good material, not easy to rip, and economical adhesive tape to secure ETT. But few studies are comparing different types of tapes used for ETT fixation.

The purpose of this study was to evaluate the force of ETT displacement or extubation when tapes of five different materials were applied for ETT fixation on a manikin.

\section{Materials and Methods}

An adult intubation manikin (Ambu, China) was orally intubated by one of the investigators using a standing intubation technique that included spraying medical lubricating fluid. An inner-diameter $7.5 \mathrm{~mm}$ ETT (wellead ${ }^{\circledR}$, Well Lead Medical co., LTD. Guangzhou, China) was inserted to $23 \mathrm{~cm}$ away from the manikin lower incisors. The cuff of ETT was inflated to a pressure of $20 \mathrm{~cm} \mathrm{H}_{2} \mathrm{O}$. Then a marker was made on the ETT just external to the manikin lower incisor to observe the displacement distance of ETT.

The ETT was secured with five different adhesive tapes used in our institution. Figure 1 shows the five different adhesive tapes. The material and brand of the five tapes in the work are listed in Table 1. All five types of tapes were split into the same dimensions (length $25 \mathrm{~cm}$, width $1.25 \mathrm{~cm}$ ), then they adhered to the ETT around the manikin cheek in random order with a conventional fixation method shown in Figure 2.

A digital push-pull force gauge (ELECALL, ELK-300, China) accurate to 0.1 Newton was attached to the proximal end of the ETT. A gradually escalating force perpendicular to the oral cavity of the manikin was applied by one of the investigators. At the same time, another investigator stabilized the manikin head to prevent movement. The digital force gauge stored the maximum force at $2 \mathrm{~cm}$ displacement and extubation. Extubation was defined as $5 \mathrm{~cm}$ ETT displacement. Each tape was tested 5 times. Intubation, ETT fixation, the observation of ETT displacement distance, and the holding manikin head were performed by 
Table 1. The material and brand of the five adhesive tapes used for endotracheal tube fixation in our institution.

\begin{tabular}{|c|c|c|c|}
\hline & Type of tape & Material & Brand and manufacturer \\
\hline Tape 1 & Transpore $^{\mathrm{TM}}$ tape & Polyethylene adhesive tape & Transpore $^{\mathrm{TM}}, 3 \mathrm{M}$ \\
\hline Tape 2 & Urgosyval $^{\circledR}$ tape & Silk adhesive tape & $\begin{array}{c}\text { Urgosyval }^{\circledR} \text {, Urgo Healthcare } \\
\text { Products Co., Ltd. Thailand }\end{array}$ \\
\hline Tape 3 & Transpore ${ }^{\mathrm{TM}}$ White tape & Non-woven fabric adhesive tape & Transpore $^{\mathrm{TM}}$ White, $3 \mathrm{M}$ \\
\hline Tape 4 & Multipore tape & Cotton elastic adhesive tape & Multipore, 3M, Japan \\
\hline Tape 5 & Durapore $^{\mathrm{TM}}$ tape & Silk adhesive tape & Durapore $^{\mathrm{TM}}, 3 \mathrm{M}$ \\
\hline
\end{tabular}

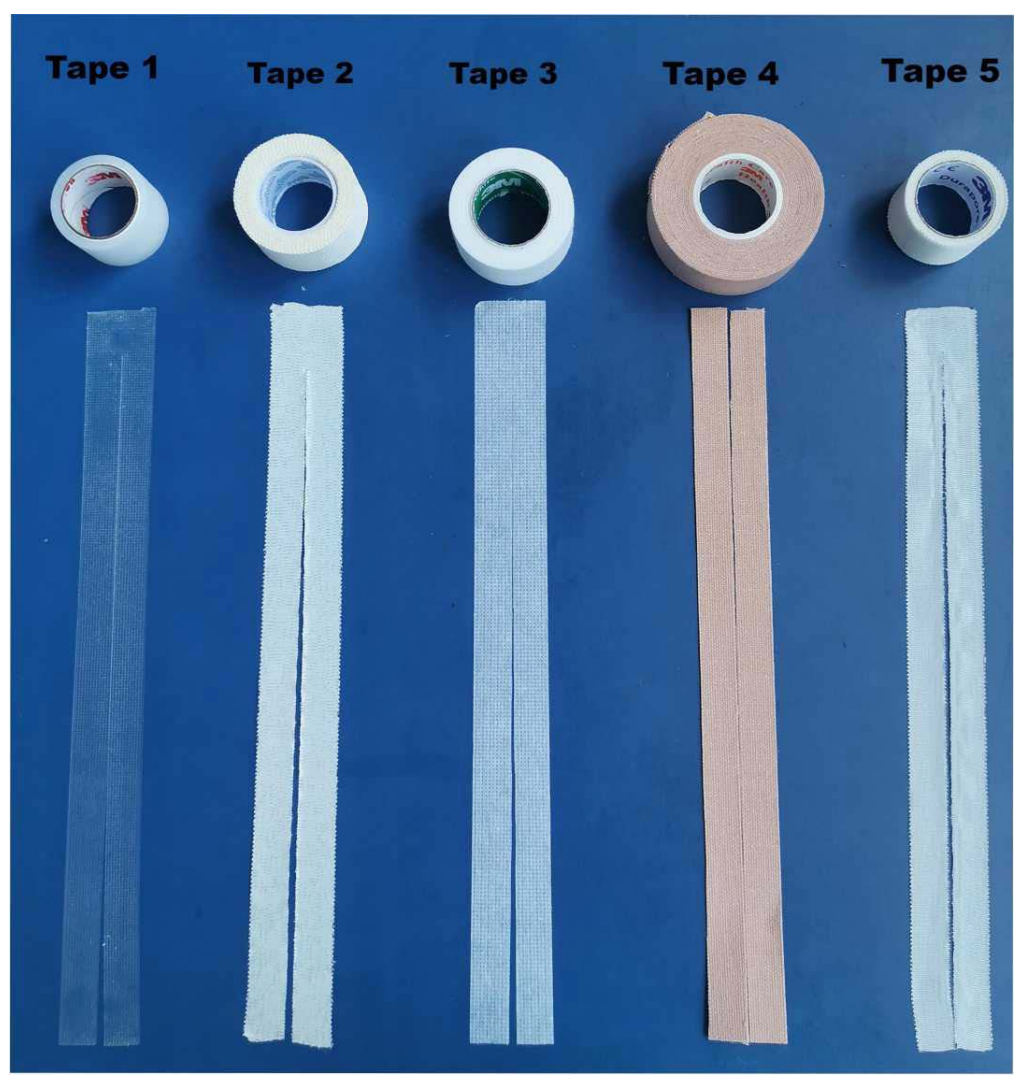

Figure 1. Five different adhesive tapes used for endotracheal tube fixation in our institution. The tapes were split into the same dimensions (length $25 \mathrm{~cm}$, width $1.25 \mathrm{~cm}$ ). Tape 1: Transpore ${ }^{\mathrm{TM}}$ tape, Tape 2: Urgosyval ${ }^{\circledR}$ tape, Tape 3: Transpore ${ }^{\mathrm{TM}}$ White tape, Tape 4: Multipore tape, Tape 5: Durapore ${ }^{\mathrm{TM}}$ tape.

the same researcher. The implementation of pulling force and recording the maximum force values were done by another researcher. A new ETT and tape were used for every test. During $2 \mathrm{~cm}$ displacement and extubation, we recorded the tape rip or not, and the adhesive state included partial or complete peeling off the surface of manikin. We also compared the cost per test of each tape to know their cost-effectiveness.

The parameters with normal distribution were expressed as mean \pm standard deviation (SD) and 95\% confidence interval (CI). The difference of force values 


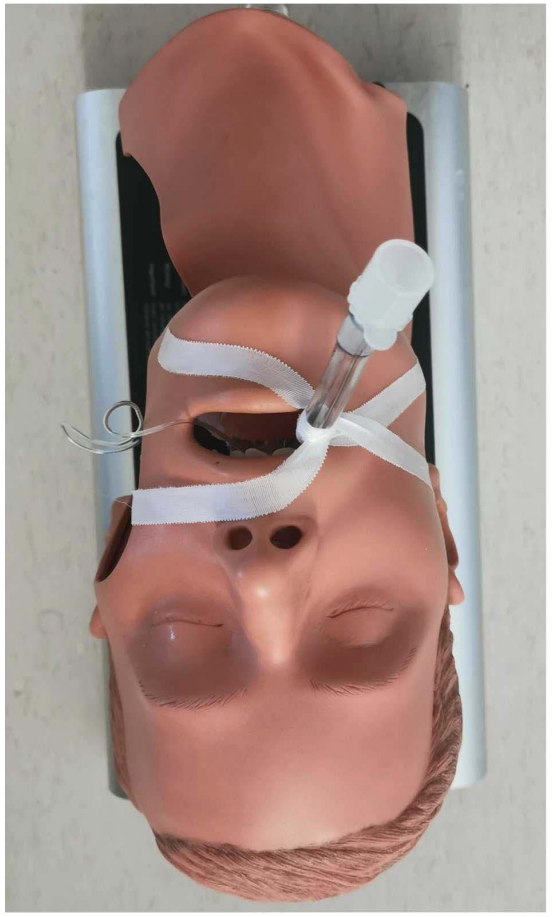

Figure 2. The conventional fixation method of endotracheal tube with tape on the manikin.

among five different tapes was assessed with one-way analysis of variance and that between groups with Bonferroni test. Statistical analysis was performed by SPSS 16.0 (SPSS Inc., USA). For all analyses, two-tailed $P$ value of less than 0.05 were considered statistically significant.

Tape was split into the same dimensions (length $25 \mathrm{~cm}$, width $1.25 \mathrm{~cm}$ ), One of them was attached to one side of the cheek, wrapped around the ETT two circles, and then cross-fixed on the same side of the cheek, and the other tape was wrapped around the ETT two circles and fixed along the upper and lower lips.

\section{Results}

Table 2 shows the force values of $2 \mathrm{~cm}$ ETT displacement and extubation with five different adhesive tapes. The force was significantly difference among the five tapes in $2 \mathrm{~cm}$ ETT displacement $(P<0.05)$. Similarly, the extubation force was significantly different $(P<0.05)$. The results of Bonferroni test between groups are shown in Figure 3. Durapore ${ }^{\mathrm{TM}}$ tape (Tape 5) had the largest average force of $2 \mathrm{~cm}$ displacement $(58.9 \pm 5.7 \mathrm{~N})$. The extubation force of Durapore ${ }^{\mathrm{TM}}$ tape was larger than $\mathrm{Urgosyval}^{\circledR}$ tape $(P<0.05)$, Transpore ${ }^{\mathrm{TM}}$ tape $(P<0.05)$, Transpore $^{\mathrm{TM}}$ White tape $(P<0.05)$. Whereas, the extubation force of Durapo$\mathrm{re}^{\mathrm{TM}}$ tape (Tape 5) and Multipore tape (Tape 4) had no significant difference.

Table 3 shows the integrity of tapes and the adhesive state of the tape-manikin interface when the ETT was moved to $2 \mathrm{~cm}$ or extubated. Urgosyval ${ }^{\circledR}$ tapes were completely peeling off surface of the manikin. Transpore ${ }^{\mathrm{TM}}$ tape and Transpo$\mathrm{re}^{\mathrm{TM}}$ White tape were ripped. 
Table 2. The force of five different adhesive tapes at $2 \mathrm{~cm}$ ETT displacement and extubation $(\mathrm{N})$.

\begin{tabular}{|c|c|c|c|c|c|c|}
\hline & \multicolumn{3}{|c|}{ Force of $2 \mathrm{~cm}$ displacement } & \multicolumn{3}{|c|}{ Extubation force } \\
\hline & \multirow{2}{*}{ mean $\pm \mathrm{SD}$} & \multicolumn{2}{|c|}{$95 \% \mathrm{CI}$} & \multirow{2}{*}{ mean $\pm \mathrm{SD}$} & \multicolumn{2}{|c|}{$95 \% \mathrm{CI}$} \\
\hline & & lower & upper & & lower & upper \\
\hline Tape 1 & $30.6 \pm 3.2$ & 33.7 & 40.6 & $37.1 \pm 2.8$ & 26.6 & 34.6 \\
\hline Tape 2 & $37.9 \pm 1.9$ & 36.9 & 43.9 & $40.4 \pm 2.9$ & 35.6 & 40.2 \\
\hline Tape 3 & $44.6 \pm 1.9$ & 42.4 & 55.0 & $48.7 \pm 5.1$ & 42.2 & 47.0 \\
\hline Tape 4 & $40.0 \pm 6.8$ & 50.3 & 58.5 & $54.4 \pm 3.3$ & 31.6 & 48.5 \\
\hline Tape 5 & $58.9 \pm 5.7$ & 53.6 & 65.7 & $59.7 \pm 4.9$ & 51.9 & 65.9 \\
\hline
\end{tabular}

Tape 1: Transpore ${ }^{\mathrm{TM}}$ tape, Tape 2: Urgosyval $^{\circledR}$ tape, Tape 3: Transpore ${ }^{\mathrm{TM}}$ White tape, Tape 4: Multipore tape, Tape 5: Durapore ${ }^{\mathrm{TM}}$ tape. ETT: endotacheal tube, SD: standard deviation, CI: confidence interval.

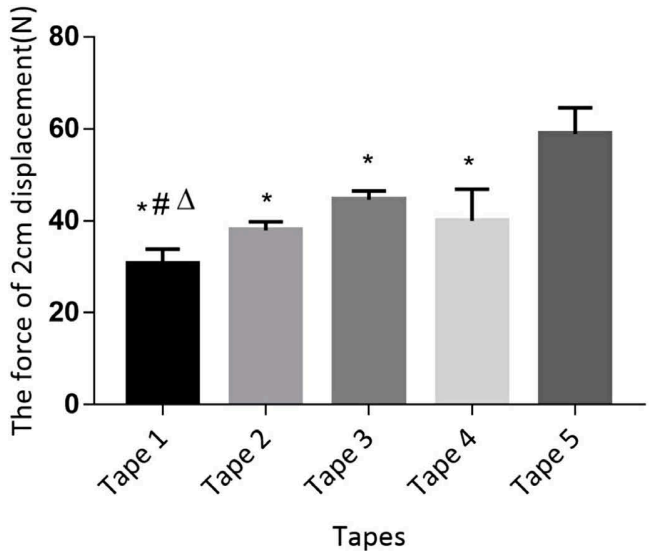

(a)

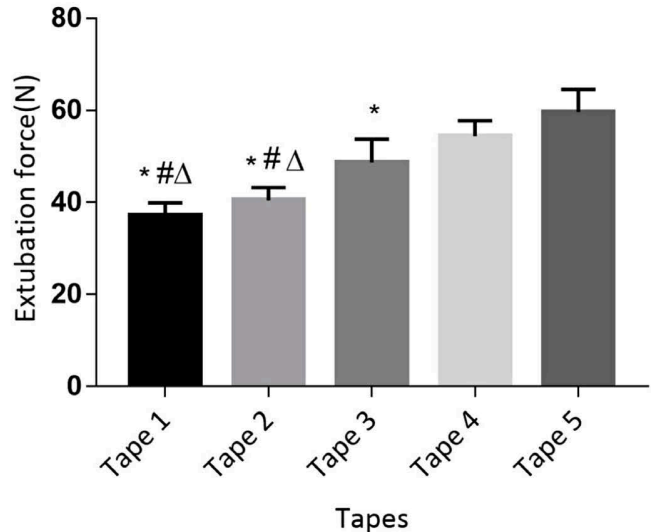

(b)

Figure 3. Comparisons of the force of $2 \mathrm{~cm}$ displacement and extubation force between different tapes used for endotracheal tube fixation on a manikin. Tape 1: Transpore ${ }^{\mathrm{TM}}$ tape, Tape 2: Urgosyval ${ }^{\circledR}$ tape, $^{-}$ Tape 3: Transpore ${ }^{\mathrm{TM}}$ White tape, Tape 4: Multipore tape, Tape 5: Durapore ${ }^{\mathrm{TM}}$ tape. ${ }^{\star} P<0.05$ compared to Tape $5 ;{ }^{\#} P<0.05$ compared to Tape $4 ;{ }^{\Delta} P<0.05$ compared to Tape 3 .

Table 3. Tape integrity and adhesive state of tape-manikin interface at $2 \mathrm{~cm}$ ETT displacement and extubation.

\begin{tabular}{ccccccccccc}
\hline & \multicolumn{4}{c}{ 2 cm displacement } & \multicolumn{3}{c}{ extubation } \\
\hline & Tape1 & Tape2 & Tape3 & Tape4 & Tape5 & Tape1 & Tape2 & Tape3 & Tape4 & Tape5 \\
\hline Partial peeling off the surface & - & - & - & - & + & - & - & - & + \\
complete peeling off the surface & - & + & - & - & - & - & + & - & - & - \\
Tape ripped & + & - & + & - & - & + & - & + & - \\
\hline
\end{tabular}

+: the event occurred, -: the event did not occur. Tape 1: Transpore ${ }^{\mathrm{TM}}$ tape, Tape 2: Urgosyval ${ }^{\circledR}$ tape, Tape 3: Transpore ${ }^{\mathrm{TM}}$ White tape, Tape 4: Multipore tape, Tape 5: Durapore ${ }^{\mathrm{TM}}$ tape, ETT: endotracheal tube.

Cost per test for 2 strips of $1.25 \mathrm{~cm} \times 25 \mathrm{~cm}$ dimensions were $¥ 0.55,0.77,0.33$, 2.45 and 0.55 for tapes from Tape 1 to Tape 5, respectively. Thus, Multipore tape (Tape 4) was the costliest and Transpore ${ }^{\mathrm{TM}}$ White (Tape 3) tape cheapest (Table 4). 
Table 4. Comparative cost analysis of the five different tapes.

\begin{tabular}{cc}
\hline Tapes & CNY/per test $(¥)^{*+}$ \\
\hline Tape 1 & 0.55 \\
Tape 2 & 0.77 \\
Tape 3 & 0.33 \\
Tape 4 & 2.45 \\
Tape 5 & 0.55 \\
\hline
\end{tabular}

${ }^{*}$ Cost per test $=2$ strips of $1.25 \mathrm{~cm} \times 25 \mathrm{~cm}$ dimension. ${ }^{+}$Cost as per our institution store prices. Tape 1 : Transpore $^{\mathrm{TM}}$ tape, Tape 2: Urgosyval $^{\circledR}$ tape, Tape 3: Transpore ${ }^{\mathrm{TM}}$ White tape, Tape 4: Multipore tape, Tape 5: Durapore ${ }^{\mathrm{TM}}$ tape.

\section{Discussion}

We compared the force values of $2 \mathrm{~cm}$ ETT displacement and extubation among five different tapes used for ETT fixation on an adult intubation manikin, the results demonstrated that Durapore ${ }^{\mathrm{TM}}$ tape was superior to the other four tapes for ETT fixation. In addition, Durapore ${ }^{\mathrm{TM}}$ tape may widely been used in the operating room because it is economical.

Securing ETT is critical for intraoperative airway management. Unplanned extubation or ETT displacement can cause serious complications, including death. Currently, the most widely used method is adhesive tape [6] [15]. Our results shown the force of $2 \mathrm{~cm}$ ETT displacement for Durapore ${ }^{\mathrm{TM}}$ tape was $58.9 \pm 5.7 \mathrm{~N}$, extubation force was $59.7 \pm 4.9 \mathrm{~N}$. Similarly, Shimizu et al. tested 3 brands of tape (Durapore $^{\mathrm{TM}}$, Multipore Dry, and Wardel) in a manikin, the results shown extubation force of Durapore ${ }^{\mathrm{TM}}$ tape in $1.3 \times 10 \mathrm{~cm}$ dimension were $49 \pm 5 \mathrm{~N}$ [9]. Another study comparing seven tube fixation methods on a laerdal intubation mannequin shown the force values of adhesive tape in $2 \mathrm{~cm}$ and $5 \mathrm{~cm}$ ETT displacement were $85 \pm 26 \mathrm{~N}$ and $144 \pm 21 \mathrm{~N}$ [16]. The possible reason that the force was greater than our results was that Lillehei method used in their study created a stabilization harness around the head of mannequin. While the Lillehei method seems unsuitable for all intubated patients with general anesthesia because it takes time to prepare and place the tape [11]. In clinical anesthesia, Lillehei method is rarely used to secure ETT. Similar to Shimizu's research [9], we used a conventional fixation method, which was more consistent with clinical routine.

We observed few differences between the force of $2 \mathrm{~cm}$ displacement and extubation force. It may be the lack of elasticity on the surface of the manikin, so a large force was required to cause $2 \mathrm{~cm}$ displacement. At the same time, the great force had caused tapes to peel off the surface of the manikin or rip. When tapes had lost their integrity and adhesiveness before extubation, force could not increase.

The extubation force of Multipore tape and Durapore ${ }^{\mathrm{TM}}$ tape were $54.4 \pm 3.3 \mathrm{~N}$ and $59.7 \pm 4.9 \mathrm{~N}$, respectively. The difference was not statistically significant. However, the force of Durapore ${ }^{\mathrm{TM}}$ tape was larger than that of Multipore tape in $2 \mathrm{~cm}$ displacement $(P<0.05)$. Since the Multipore tape is a cotton elastic adhe- 
sive tape, we speculate that a small force may cause $2 \mathrm{~cm}$ displacement due to its elasticity. Therefore, the effect of Durapore ${ }^{\mathrm{TM}}$ tape to secure ETT is better than Multipore tape.

Our study had several limitations. First, the manikin surface cannot match the structural properties of the human skin surface completely. Second, certain factors encountered in clinical practice, such as vomit, facial grease, disinfectant, beards, and oral secretions were not mimicked in our simulation. So the effect of these tapes on real cases needs to be confirmed by clinical trials. Third, the force we applied to ETT was in the same direction, whereas the force encountered during the operation with general anesthesia may be multidirectional and rapidly changing. Furthermore, we only measured the force of a single dimension of the tapes, whereas increasing the width and length of the tape may increase the force of displacement and extubation. Finally, head rotation is also a potential cause of extubation or displacement, but we limited the manikin head in anatomic position.

\section{Conclusion}

In conclusion, Durapore ${ }^{\mathrm{TM}}$ tape used for ETT fixation on the manikin is superior to the other four tapes (Transpore ${ }^{\mathrm{TM}}$ tape, Urgosyval tape ${ }^{\circledR}$, Transpore ${ }^{\mathrm{TM}}$ White tape, Multipore tape), and it is economical. The effect of different adhesive tapes on patients needs to be confirmed by clinical trials.

\section{Acknowledgements}

We thank the department of Intensive Critical Care, the Sixth Affiliated Hospital, Sun Yat-sen University for providing the intubation manikin.

\section{Authors' Contributions}

Sanqing Jin designed the study and supervised the whole process of the study and revised the manuscript. Dongxue Li and Xia Huang collected and analyzed the data, and Dongxue Li wrote the manuscript.

\section{Conflicts of Interest}

All authors have no interests to be declared.

\section{References}

[1] Wang, H.E., Kupas, D.F., Paris, P.M., Bates, R.R. and Yealy, D.M. (2003) Preliminary Experience with a Prospective, Multi-Centered Evaluation of Out-of-Hospital Endotracheal Intubation. Resuscitation, 58, 49-58. https://doi.org/10.1016/S0300-9572(03)00058-3

[2] Tailleur, R., Bathory, I., Dolci, M., Frascarolo, P., Kern, C. and Schoettker, P. (2016) Endotracheal Tube Displacement during Head and Neck Movements. Observational Clinical Trial. Journal of Clinical Anesthesia, 32, 54-58. https://doi.org/10.1016/j.jclinane.2015.12.043

[3] Kambestad, K.K., Huack, A., Nair, S., Chapman, R., Chin, S., Langga, L., et al. (2019) 
The Adverse Impact of Unplanned Extubation in a Cohort of Critically Ill Neonates. Respiratory Care, 64, 1500-1507. https://doi.org/10.4187/respcare.06721

[4] da Silva, P.S.L. and Fonseca, M.C. (2012) Unplanned Endotracheal Extubations in the Intensive Care Unit: Systematic Review, Critical Appraisal, and Evidence-Based Recommendations. Anesthesia \& Analgesia, 114, 1003-1014. https://doi.org/10.1213/ANE.0b013e31824b0296

[5] Boulain, T. (1998) Unplanned Extubations in the Adult Intensive Care Unit: A Prospective Multicenter Study. Association Des Réanimateurs Du Centre-Ouest. American Journal of Respiratory and Critical Care Medicine, 157, 1131-1137. https://doi.org/10.1164/ajrccm.157.4.9702083

[6] Atkins, P.M., Mion, L.C., Mendelson, W., Palmer, R.M., Slomka, J. and Franko, T. (1997) Characteristics and Outcomes of Patients Who Self-Extubate from Ventilatory Support: A Case-Control Study. Chest, 112, 1317-1323. https://doi.org/10.1378/chest.112.5.1317

[7] Coppolo, D.P. and May, J.J. (1990) Self-Extubations. A 12-Month Experience. Chest, 98, 165-169. https://doi.org/10.1378/chest.98.1.165

[8] Carlson, J., Mayrose, J., Krause, R. and Jehle, D. (2007) Extubation Force: Tape versus Endotracheal Tube Holders. Annals of Emergency Medicine, 50, 686-691. https://doi.org/10.1016/j.annemergmed.2007.05.013

[9] Shimizu, T., Mizutani, T., Yamashita, S., Hagiya, K. and Tanaka, M. (2011) Endotracheal Tube Extubation Force: Adhesive Tape versus Endotracheal Tube Holder. Respiratory Care, 56, 1825-1829. https://doi.org/10.4187/respcare.00954

[10] Buckley, J.C., Brown, A.P., Shin, J.S., Rogers, K.M. and Hoftman, N.N. (2016) A Comparison of the Haider Tube-Guard ${ }^{\circledast}$ Endotracheal Tube Holder versus Adhesive Tape to Determine if this Novel Device Can Reduce Endotracheal Tube Movement and Prevent Unplanned Extubation. Anesthesia \& Analgesia, 122, 1439-1443. https://doi.org/10.1213/ANE.0000000000001222

[11] Owen, R., Castle, N., Hann, H., Reeves, D., Naidoo, R. and Naidoo, S. (2009) Extubation Force: A Comparison of Adhesive Tape, Non-Adhesive Tape and a Commercial Endotracheal Tube Holder. Resuscitation, 80, 1296-1300. https://doi.org/10.1016/j.resuscitation.2009.08.007

[12] Landsperger, J.S., Byram, J.M., Lloyd, B.D. and Rice, T.W. (2019) The Effect of Adhesive Tape Versus Endotracheal Tube Fastener in Critically Ill Adults: The Endotracheal Tube Securement (ETTS) Randomized Controlled Trial. Critical Care, 23, Article No. 161. https://doi.org/10.1186/s13054-019-2440-7

[13] Murdoch, E. and Holdgate, A. (2007) A Comparison of Tape-Tying versus a TubeHolding Device for Securing Endotracheal Tubes in Adults. Anaesthesia and Intensive Care, 35, 730-735. https://doi.org/10.1177/0310057X0703500512

[14] Gardner, A., Hughes, D., Cook, R., Henson, R., Osborne, S. and Gardner, G. (2005) Best Practice in Stabilisation of Oral Endotracheal Tubes: A Systematic Review. Australian Critical Care, 18, 158-165. https://doi.org/10.1016/S1036-7314(05)80029-3

[15] Kapadia, F.N., Bajan, K.B. and Raje, K.V. (2000) Airway Accidents in Intubated Intensive Care Unit Patients: An Epidemiological Study. Critical Care Medicine, 28, 659-664. https://doi.org/10.1097/00003246-200003000-00010

[16] Wagner, J.L., Shandas, R. and Lanning, C.J. (2014) Extubation Force Depends upon Angle of Force Application and Fixation Technique: A Study of 7 Methods. BMC Anesthesiology, 14, Article No. 74. https://doi.org/10.1186/1471-2253-14-74 